\title{
A Prospective Multicentric Study of Pulmonary Rehabilitation in Patients with Chronic Obstructive Pulmonary Disease and Different Clinical Phenotypes
}

\author{
Nicolino Ambrosino ${ }^{a}$ Elena Venturellib ${ }^{b}$ Francesco de Blasio ${ }^{c}$ \\ Pierluigi Paggiaro $^{d}$ Franco Pasqua $^{\mathrm{e}}$ Michele Vitaccaf ${ }^{\mathrm{f}}$ Guido Vaghegginia \\ Enrico M. Clini ${ }^{\text {b }}$ \\ a'Weaning and Rehabilitation Unit, Auxilium Vitae Rehabilitation Center, Volterra, b University of Modena and \\ Reggio Emilia, Scienze Mediche e Chirurgiche Materno-Infantili e dell'adulto, Modena, 'Clinic Center, Pulmonary \\ Rehabilitation, Napoli, ${ }^{d}$ University Hospital, Cardiothoracic and Vascular Department, Pisa, ${ }^{e}$ Pneumology

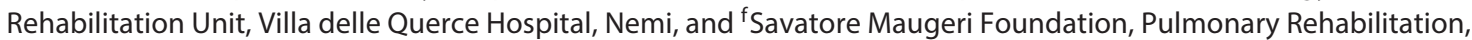 \\ Medical Center, Lumezzane, Italy
}

\section{Key Words}

Exercise training $\cdot$ Dyspnea $\cdot$ Health related quality of life .

Pulmonary emphisema $\cdot$ Respiratory muscles

\begin{abstract}
Background: Recently, it has been proposed that different clinical phenotypes can be recognized in patients with chronic obstructive disease (COPD), namely predominant airway disease or parenchymal destructive changes. Objectives: The aim of this prospective multicenter study was to evaluate whether these two phenotypes may influence outcomes following a pulmonary rehabilitation program (PRP). Methods: We have prospectively evaluated 364 consecutive COPD patients (70 \pm 8 years, $76.3 \%$ males) admitted to a standard hospital-based PRP in 6 Italian centers. According to their phenotype, the study cohort was divided into two groups: patients with airway obstructive (group $1, \mathrm{n}=208$ ) or parenchymal destructive COPD (group $2, n=156$ ). Before and after PRP, values of 6-min walking distance, perceived
\end{abstract}

(c) 2015 S. Karger AG, Basel

0025-7931/15/0892-0141\$39.50/0 breathlessness (Medical Research Council), health-related quality of life (St. George's Respiratory Questionnaire) and respiratory muscle function (maximal inspiratory and expiratory pressure) were recorded. Results: PRP resulted in significant improvements in all outcome measures without any significant differences between groups. Conclusions: Our study confirms that COPD patients may benefit from pulmonary rehabilitation independent of their clinical phenotype.

(c) 2015 S. Karger AG, Basel

\section{Introduction}

Chronic obstructive pulmonary disease (COPD) is a complex disease involving the lungs and is characterized by slowly progressive expiratory airflow limitation, which is not fully reversible [1]. This disease includes heterogeneous conditions with different clinical, functional and radiological features, and it is associated with several comorbidities [2]. Recently, it has been proposed that COPD

\section{KARGER 125}

E-Mail karger@karger.com www.karger.com/res
Nicolino Ambrosino

Auxilium Vitae

Borgo S. Lazzaro 5

IT-56048 Volterra (Italy)

E-Mail nico.ambrosino@gmail.com 
patients present with different clinical phenotypes, namely predominant airway disease or predominant parenchymal destructive changes $[3,4]$.

Disability is common in COPD, and both pulmonary and extrapulmonary factors are important in predicting COPD development [5]. Pulmonary rehabilitation is recognized as a core component of the comprehensive management of COPD patients [6]. Following a pulmonary rehabilitation program (PRP), patients report improvements in health-related quality of life (HRQL), relief of respiratory and extrapulmonary symptoms, increased exercise tolerance and a greater level of independence in the performance of activities of daily living [7]. This is also true when complex comorbidities [8] or limited functional residual capacity (FRC) following acute exacerbations are present [9].

To date, there are still few data on the effect of PRP in COPD patients with respect to their clinical phenotypes. Recent evidence suggested that PRP including exercise training may improve cardiovascular response with enhanced ventilatory function in an unselected population of COPD patients [10], thus suggesting that patients with hyperinflation should not be excluded from this program. The effect of PRP in patients with severe emphysema has been evaluated only in patients who are candidates for lung volume reduction surgery [11].

It has been shown that resting hyperinflation is associated with reduced exercise tolerance and increased mortality in COPD patients [12]. Therefore, we wondered whether patients with more severe hyperinflation would get less benefit from PRP.

In our large retrospective observational study, COPD patients with lung hyperinflation were likely to gain benefit from a standard PRP in terms of both exercise tolerance, gas exchange and perceived symptoms during effort [13]. The aim of this prospective multicentric study was to evaluate differences in PRP outcomes (if any) according to COPD phenotypes, either predominant airway disease or predominant parenchymal destructive changes. Potential differences in the effectiveness of PRP might help in the selection of candidates for standard PRP.

\section{Patients and Methods}

\section{Patients}

The protocol has been approved (approval 76/11, 10-05-2011) by the Ethical Committee of the University Hospital of Modena (Italy), and the trial has been registered at ClinicalTrial.gov (code NCT01305668). Informed consent was signed by all the patients.

Consecutive COPD patients recovering from an acute exacerbation of their disease and referred to the pulmonary rehabilitation units of 6 Italian centers (Villa Pineta Hospital, Pavullo nel Frignano; Auxilium Vitae, Volterra; Salvatore Maugeri Foundation IRCCS, Lumezzane; San Raffaele Hospital, Montecompatri; Clinic Center, Napoli, and University Hospital, Pisa) to undergo either an in- or an outpatient hospital-based PRP were studied from January 2012 to December 2013.

Diagnosis and severity of COPD were confirmed by spirometry and described according to the Global Initiative for Chronic Obstructive Lung Disease (GOLD) guidelines and classification [1]. All patients were admitted after an exacerbation of their disease requiring hospital admission. Patients were transferred to a rehabilitation center after discharge from the acute hospital, as described elsewhere $[9,14]$. In all cases, referral to PRP was within 10 days following acute care. On admission, all patients had stopped smoking and were in stable condition, which was assessed by the absence of symptom worsening, i.e. no change in the patient's baseline dyspnea, cough and/or sputum beyond day-to-day variability sufficient to warrant a change in management, and no substantial changes in arterial blood gases. Patients unable to cooperate were excluded from the study. All patients received appropriate regular treatment with long-term bronchodilators and inhaled corticosteroids, if required, according to the current guidelines for COPD [1].

\section{Definition of Phenotypes}

Patients in our study were divided into two groups: patients with predominant airway disease (group 1) and those with predominant parenchymal destructive disease (group 2) according to the model derived from a multivariate analysis in a cohort of COPD patients proposed by Pistolesi et al. [3]. Briefly, patient analysis allows to cluster two relevant groups of patients, those with the emphysematous phenotype and those with the bronchial phenotype, on the basis of clinical, functional and instrumental variables. Nine variables are collected in routine clinical care, four are derived from the patient's history and physical examination (sputum characteristics, adventitious sounds and hyperresonance), four from chest radiography (increased vascular markings, bronchial wall thickening, increased lung volume and reduced lung density) and one from spirometry [forced expiratory volume in $1 \mathrm{~s}\left(\mathrm{FEV}_{1}\right) /$ vital capacity) [3].

\section{Pulmonary Rehabilitation Program}

Patients of both groups actively participated in a multidisciplinary protocol of hospital-based PRP sessions $(n=15-21)$, including the optimization of drug therapy and daily activities, which include supervised incremental exercises on a treadmill or a cycle ergometer according to the protocol suggested by Maltais et al. [15] until the achievement of 30 min of continuous exercise at an intensity that elicited dyspnea at level 5 on the modified Borg scale [16]; abdominal, upper- and lower-limb muscle training involving lifting of progressively increasing light weights, and shoulder and full-arm circling; education for participants and family members; nutritional programs and psychosocial counseling, if appropriate. A multidisciplinary team of chest physicians, nurses, physical therapists, a dietician and a psychologist offered appropriate care and support.

\section{Measurements and Outcomes}

The impact of comorbidity by the self-reported Charlson index [17] was recorded in all patients to characterize the complexity of their disease. 
On admission, lung function tests were assessed in the morning by spirometry to record both static and dynamic lung volumes. Recordings were assessed after bronchodilation and expressed as absolute and percent of predicted values according to Quanjer [18]. Arterial blood gases were assessed by means of analyzers, using blood samples drawn from the radial artery while patients breathed room air in the sitting position.

Before and after PRP, patients underwent evaluation of the following outcome measures. Inspiratory and expiratory muscle function was evaluated assessing maximal inspiratory (MIP) and expiratory (MEP) static pressures at the level of FRC and total lung capacity (TLC), respectively, according to the method of Black and Hyatt [19]; predicted values were those of Bruschi et al. [20]. Patients performed a minimum of three maneuvers with at least a 1-min interval between efforts until two acceptable values not differing from each other by more than $5 \%$ were obtained. The best value was recorded.

Exercise tolerance was assessed by means of the 6-minute walking test (6MWT) according to American Thoracic Society guidelines [21]. The best of two consecutive performances (2-hour apart) conducted in a 30-m long and 3-m wide corridor under quiet conditions and without distractive stimuli was recorded for analysis. At the beginning and at the end of walking, subjective sensation of both dyspnea and leg fatigue was assessed by means of the modified Borg scale [16]. The clinically minimal important difference (MID) in the 6MWT following exercise training in moderate-to-severe COPD was recently reported to be at least a 33 meter increase [22].

Subjective sensation of breathlessness was evaluated by means of the Medical Research Council (MRC) scale [23]. A 1 -point change in the scale is considered the MID for this outcome [24].

Perceived HRQL was measured by the validated Italian version of the St. George's Respiratory Questionnaire (SGRQ) [25]. This is a disease-specific score assessment of self-reported HRQL that has been extensively studied in patients with all grades of respiratory disease, including advanced COPD [26]. The questionnaire consists of 76 items divided into three main domains (symptoms, activity and impact). The total and domain scores range from 0 (perfect health) to 100 (worst possible). A 4-unit score reduction is considered to be the MID for this outcome measure [27].

Finally, the composite and multidimensional body mass, obstruction, dyspnea and exercise (BODE) index [28] was calculated in each patient. It has been shown that for every point increase in the BODE index there is a corresponding increase in mortality [29].

\section{Statistical Analysis}

Due to the explorative nature of the study, we did not perform any formal sample size study. Indeed, our previous retrospective study [13] in more than 600 subjects informed about the possible lack of difference in PRP outcome in COPD patients with or without lung hyperinflation. Therefore, the present multicenter analysis was designed to confirm those findings by including all consecutive patients admitted to each center in the study period and fulfilling the inclusion criteria.

Analyses were performed using a specific package (SPSS for Windows, latest version; SPSS, Chicago, Ill., USA). Descriptive categorical variables are expressed as frequency or percent values, whereas scale variables are expressed as means \pm SD.

Clinical Phenotypes of COPD and Rehabilitation
The unpaired t test, Kruskal-Wallis $\mathrm{H}$ test, and $\chi^{2}$ analyses for dichotomous variables were used when appropriate for comparisons between groups to test any baseline difference in parametric and nonparametric variables. The within- and between-group differences in PRP outcomes were assessed by paired-sample $t$ and Wilcoxon tests. Pearson's correlation coefficient analysis and linear regression model between primary outcome change ( $\triangle 6 \mathrm{MWT})$ and any baseline measurement were then applied to all the patients of both groups. A value of $\mathrm{p}<0.05$ was considered to be statistically significant.

The proportions (\%) of patients reaching the MID in 6MWT, SGRQ, MRC and BODE were also reported for each group.

\section{Results}

Two hundred and eight patients (57.7\%) with predominant airway disease (group 1) and 156 patients with predominant parenchymal disease (group 2) were enrolled in the study. The two clinical phenotypes were homogeneously distributed across centers, which followed standardized and agreed-upon operating procedures [13]; therefore, patients' general characteristics, PRP process and delivery, and assessment of outcomes were similar and reliable, too. There was no significant difference in long-term drug therapy between the two groups.

Demographic, anthropometric and physiological characteristics of the patients on admission, as well as their distribution across the GOLD classes, are described in table 1 for all patients and each group separately. As expected, patients of group 2 suffered from more severe airway obstruction, hyperinflation and dyspnea, and had a worse composite BODE index compared to patients of group 1. On the other hand, patients of group 1 were characterized by a higher number of self-reported comorbidities as assessed by the Charlson index. The course of PRP consisted of $19 \pm 3$ and $20 \pm 5$ sessions in groups 1 and 2, respectively.

Main outcomes in two groups before and after PRP are shown in table 2. Standard rehabilitation resulted in significant benefits and improvement in all the considered measures; moreover, the changes in the main outcomes were similar in the two patient groups.

The proportions of patients reaching the MID in postPRP 6MWT, MRC, SGRQ and BODE are shown in table 3. There was no significant difference in MID for any outcome between the two groups.

The results of the Pearson's coefficient analysis between $\triangle 6 \mathrm{MWT}$ and variables taken on admission in both groups are shown in table 4 , which indicate a significant correlation with forced vital capacity (FVC, in \% of pre- 
Table 1. Demographic, anthropometric, physiological and clinical characteristics of the study patients

\begin{tabular}{|c|c|c|c|c|}
\hline & $\begin{array}{l}\text { All subjects } \\
(\mathrm{n}=364)\end{array}$ & $\begin{array}{l}\text { Group 1 } \\
(\mathrm{n}=208)\end{array}$ & $\begin{array}{l}\text { Group 2 } \\
(\mathrm{n}=156)\end{array}$ & $\mathrm{p}$ value \\
\hline Age, years & $70.1 \pm 7.9$ & $70.5 \pm 8.2$ & $69.5 \pm 7.6$ & 0.236 \\
\hline Males:females & $278: 86$ & $162: 46$ & $116: 40$ & 0.43 \\
\hline BMI, $\mathrm{kg} / \mathrm{m}^{2}$ & $26.5 \pm 5.4$ & $26.8 \pm 5.4$ & $26.0 \pm 5.3$ & 0.174 \\
\hline BODE, score & $4.1 \pm 2.2$ & $3.8 \pm 2.1$ & $4.6 \pm 2.2$ & 0.001 \\
\hline Pack-years & $45.6 \pm 25.5$ & $44.6 \pm 26.6$ & $47.1 \pm 23.8$ & 0.408 \\
\hline GOLD I, n (\%) & $17(4.7)$ & $13(6.2)$ & $4(2.6)$ & 0.162 \\
\hline GOLD II, n (\%) & $138(37.9)$ & $92(44.2)$ & $46(29.4)$ & 0.006 \\
\hline GOLD III, n (\%) & $147(40.4)$ & $80(38.4)$ & $67(42.9)$ & 0.050 \\
\hline GOLD IV, n (\%) & $62(17.0)$ & $23(11.0)$ & $39(25.0)$ & 0.001 \\
\hline $\mathrm{FEV}_{1}$, liters & $1.21 \pm 0.50$ & $1.30 \pm 0.51$ & $1.09 \pm 0.45$ & 0.0001 \\
\hline $\mathrm{FEV}_{1}, \%$ of pred. & $47.5 \pm 18.0$ & $50.9 \pm 18.5$ & $42.9 \pm 16.4$ & 0.0001 \\
\hline FVC, liters & $2.50 \pm 0.85$ & $2.57 \pm 0.85$ & $2.40 \pm 0.83$ & 0.071 \\
\hline FVC, $\%$ of pred. & $75.7 \pm 23.7$ & $77.6 \pm 23.1$ & $73.2 \pm 24.4$ & 0.085 \\
\hline $\mathrm{FEV}_{1} / \mathrm{FVC}, \%$ & $49.1 \pm 12.3$ & $51.2 \pm 11.5$ & $46.4 \pm 12.8$ & 0.0001 \\
\hline TLC, liters & $6.90 \pm 1.47$ & $6.83 \pm 1.51$ & $7.02 \pm 1.41$ & 0.331 \\
\hline TLC, \% of pred. & $119.7 \pm 23.1$ & $117.1 \pm 22.9$ & $123.8 \pm 22.9$ & 0.030 \\
\hline $\mathrm{RV}$, liters & $4.33 \pm 1.54$ & $4.16 \pm 1.52$ & $4.59 \pm 1.53$ & 0.033 \\
\hline $\mathrm{RV}, \%$ of pred. & $182.2 \pm 62.3$ & $172.1 \pm 62.6$ & $198.3 \pm 58.5$ & 0.001 \\
\hline RV/TLC, $\%$ & $60.3 \pm 12.6$ & $58.8 \pm 11.7$ & $62.7 \pm 13.6$ & 0.021 \\
\hline FRC, liters & $5.51 \pm 3.85$ & $5.36 \pm 3.96$ & $5.78 \pm 3.67$ & 0.478 \\
\hline FRC, $\%$ of pred. & $153.8 \pm 41.8$ & $147.1 \pm 40.3$ & $165.9 \pm 42.1$ & 0.003 \\
\hline IC, liters & $2.16 \pm 0.68$ & $2.22 \pm 0.70$ & $2.06 \pm 0.62$ & 0.072 \\
\hline IC, \% of pred. & $82.4 \pm 21.5$ & $82.4 \pm 22.6$ & $82.4 \pm 19.1$ & 0.999 \\
\hline Charlson index & $1.1 \pm 1.4$ & $1.3 \pm 1.5$ & $0.9 \pm 1.3$ & 0.025 \\
\hline $\mathrm{pH}$ & $7.41 \pm 0.02$ & $7.41 \pm 0.02$ & $7.41 \pm 0.03$ & 0.945 \\
\hline $\mathrm{PaO}_{2}, \mathrm{~mm} \mathrm{Hg}$ & $68.6 \pm 10.2$ & $68.4 \pm 10.1$ & $68.9 \pm 10.4$ & 0.678 \\
\hline $\mathrm{PaCO}_{2}, \mathrm{~mm} \mathrm{Hg}$ & $42.8 \pm 7.7$ & $42.5 \pm 7.3$ & $43.3 \pm 8.3$ & 0.346 \\
\hline $\mathrm{PaO}_{2} / \mathrm{FiO}_{2}$ & $322.1 \pm 48.9$ & $322.2 \pm 48.3$ & $322.1 \pm 49.9$ & 0.983 \\
\hline $\mathrm{MIP}, \mathrm{cm} \mathrm{H}_{2} \mathrm{O}$ & $62.4 \pm 24.5$ & $63.4 \pm 24.1$ & $61.1 \pm 25.1$ & 0.446 \\
\hline $\mathrm{MEP}, \mathrm{cm} \mathrm{H}_{2} \mathrm{O}$ & $94.9 \pm 37.8$ & $98.8 \pm 36.5$ & $89.6 \pm 38.9$ & 0.047 \\
\hline 6MWT, m & $339.3 \pm 145.5$ & $346.9 \pm 141.4$ & $329.0 \pm 150.7$ & 0.253 \\
\hline MRC, score & $2.5 \pm 0.9$ & $2.4 \pm 0.9$ & $2.6 \pm 0.9$ & 0.021 \\
\hline SGRQ total score & $45.65 \pm 16.60$ & $46.4 \pm 17.5$ & $44.9 \pm 16.3$ & 0.441 \\
\hline
\end{tabular}

$\mathrm{BMI}=$ Body mass index $\mathrm{IC}=$ inspiratory capacity $\mathrm{PaO}_{2}=$ arterial oxygen tension $; \mathrm{FiO}_{2}=$ fraction of inspired oxygen. $\mathrm{p}$ values refer to between-group comparisons.

Table 2. Changes in outcome measures throughout PRP

\begin{tabular}{|c|c|c|c|c|c|c|c|}
\hline & \multicolumn{3}{|l|}{ Group 1} & \multicolumn{4}{|l|}{ Group 2} \\
\hline & before & after & $\mathrm{p}$ value & before & after & $\mathrm{p}$ value & $\mathrm{p} 1$ \\
\hline BODE & $3.8 \pm 2.1$ & $2.7 \pm 1.8$ & 0.0001 & $4.6 \pm 2.2$ & $3.4 \pm 2.0$ & 0.0001 & 0.250 \\
\hline $\mathrm{MIP}, \mathrm{cm} \mathrm{H}_{2} \mathrm{O}$ & $63.8 \pm 23.3$ & $70.3 \pm 24.2$ & 0.0001 & $60.2 \pm 24.4$ & $66.4 \pm 26.6$ & 0.0001 & 0.820 \\
\hline $\mathrm{MEP}, \mathrm{cm} \mathrm{H}_{2} \mathrm{O}$ & $98.0 \pm 38.2$ & $111.4 \pm 42.0$ & 0.0001 & $88.5 \pm 38.4$ & $99.2 \pm 40.4$ & 0.0001 & 0.212 \\
\hline $6 \mathrm{MWT}, \mathrm{m}$ & $347.2 \pm 142.2$ & $412.0 \pm 131.7$ & 0.0001 & $325.8 \pm 151.3$ & $389.9 \pm 134.9$ & 0.0001 & 0.921 \\
\hline MRC, score & $2.4 \pm 0.9$ & $1.5 \pm 0.8$ & 0.0001 & $2.6 \pm 0.9$ & $1.7 \pm 0.9$ & 0.0001 & 0.469 \\
\hline SGRQ-symptoms & $46.0 \pm 25.7$ & $32.5 \pm 21.1$ & 0.0001 & $43.5 \pm 22.2$ & $33.5 \pm 21.8$ & 0.0001 & 0.063 \\
\hline SGRQ-activities & $61.3 \pm 18.4$ & $54.2 \pm 19.0$ & 0.014 & $59.1 \pm 20.1$ & $52.8 \pm 22.2$ & 0.0001 & 0.728 \\
\hline SGRQ-impact & $33.9 \pm 17.9$ & $27.1 \pm 17.4$ & 0.034 & $30.8 \pm 15.5$ & $25.1 \pm 15.3$ & 0.0001 & 0.177 \\
\hline SGRQ-total & $46.0 \pm 17.6$ & $37.1 \pm 17.2$ & 0.0001 & $45.5 \pm 16.1$ & $36.9 \pm 16.7$ & 0.0001 & 0.899 \\
\hline
\end{tabular}

p1 refers to differences in outcome measure changes. Significant differences are in bold. 
Table 3. Proportion (\%) of patients reaching the MID in the postPRP evaluation

\begin{tabular}{lllll}
\hline & All subjects & Group 1 & Group 2 & p value \\
\hline 6MWT & 66.9 & 68.1 & 65.3 & 0.659 \\
MRC & 69.3 & 68.8 & 70.1 & 0.888 \\
SGRQ total score & 70.8 & 68.6 & 73.6 & 0.416 \\
BODE & 73.4 & 70.2 & 77.5 & 0.115 \\
\hline
\end{tabular}

$\mathrm{p}$ values refer to between-group comparisons.

Table 4. Pearson's correlation coefficients of $\Delta 6 \mathrm{MWT}$ and baseline clinical parameters in both study groups

\begin{tabular}{|c|c|c|c|}
\hline & \multicolumn{3}{|l|}{$\Delta 6 \mathrm{MWT}$} \\
\hline & $\begin{array}{l}\text { Pearson's } \\
\text { correlation }\end{array}$ & $\begin{array}{l}\text { sig. } \\
\text { (2-tailed) }\end{array}$ & $\mathrm{n}$ \\
\hline Age & -0.098 & 0.168 & 201 \\
\hline BMI & -0.13 & 0.070 & 195 \\
\hline $\mathrm{FEV}_{1}$ & -0.012 & 0.866 & 202 \\
\hline $\mathrm{FEV}_{1} \%$ & -0.074 & 0.292 & 202 \\
\hline FVC & -0.076 & 0.279 & 202 \\
\hline FVC\% & -0.142 & $0.044^{*}$ & 201 \\
\hline TLC & 0.088 & 0.291 & 147 \\
\hline TLC\% & 0.149 & 0.075 & 143 \\
\hline RV & 0.162 & $0.049 *$ & 147 \\
\hline RV\% & 0.205 & $0.014^{*}$ & 144 \\
\hline RV/TLC\% & 0.238 & $0.005^{* *}$ & 135 \\
\hline FRC & 0.153 & 0.105 & 113 \\
\hline FRC\% & 0.222 & $0.017^{*}$ & 114 \\
\hline $\mathrm{pH}$ & 0.058 & 0.419 & 198 \\
\hline $\mathrm{PaO}_{2}$ & -0.09 & 0.209 & 198 \\
\hline $\mathrm{PaCO}_{2}$ & 0.152 & 0.033* & 198 \\
\hline $\mathrm{HCO}_{3}$ & 0.14 & 0.074 & 163 \\
\hline $\mathrm{PaO}_{2} / \mathrm{FIO}_{2}$ & -0.058 & 0.419 & 198 \\
\hline $\mathrm{MIP}_{1}$ & -0.003 & 0.970 & 151 \\
\hline $\mathrm{MEP}_{1}$ & -0.048 & 0.561 & 149 \\
\hline 6MWD, baseline & -0.39 & $0.000^{* *}$ & 200 \\
\hline Charlson index & -0.024 & 0.744 & 183 \\
\hline MRC, baseline & 0.24 & $0.001^{* *}$ & 200 \\
\hline
\end{tabular}

$\mathrm{BMI}=$ Body mass index $\mathrm{PaO}_{2}=$ arterial oxygen tension; $\mathrm{FiO}_{2}=$ fraction of inspired oxygen. Parameters with significant direct correlation $(\mathrm{p}<0.05)$ are in bold.

dicted), indexes of hyperinflation like residual volume (RV) and RV/TLC ratio, arterial carbon dioxide tension $\left(\mathrm{PaCO}_{2}\right)$, baseline 6MWT and baseline MRC.

These parameters were then input into the linear regression model that showed baseline 6MWT $(\mathrm{p}<0.005)$ to be the only variable that inversely correlated and significantly predicted the changes in primary outcome following pulmonary rehabilitation in these patients.

\section{Discussion}

This is the first prospective multicenter study showing that a formal and standard PRP results in substantial benefits in COPD patients independent of their prevalent clinical phenotype, either airway disease or parenchymal destruction.

In a previous observational albeit retrospective study, we had already reported that COPD patients with impaired pulmonary mechanics due to lung hyperinflation might benefit from standard PRP and improve more in exercise tolerance, gas exchange and perceived symptoms during submaximal effort compared with patients without PRP [13] notwithstanding that retrospective analysis had some clear limitations related to the patient selection and the physiological definition of lung hyperinflation. Indeed, hyperinflation was exclusively based on the recording of the residual lung volumes without any quantitative or qualitative emphysema score confirming the parenchymal destruction. Screening tests to identify patients who are susceptible to developing dynamic hyperinflation during exercise and/or activities in the daily living should be assessed [30].

In this prospective study, although we did not use lung CT scans, we used a reliable and accepted methodology to define different clinical phenotypes [3] in the COPD population to confirm those findings.

As expected, compared with patients with the airway bronchial phenotype, patients with parenchymal destruction had more severe lung dysfunction and perceived dyspnea. Moreover, the composite BODE index was worse in patients of group 2, the difference being related to worse airway obstruction and dyspnea but not to exercise tolerance. It has been shown that PRP may improve the BODE index and is associated with better outcomes, and that the BODE index changes after PRP provides valuable information [29].

In our study, the impact of comorbidities, which were assessed by the Charlson index, in the population of COPD referred for rehabilitation is in line with that reported previously [8], being significantly although slightly higher in individuals of group 1. The lack of differences in outcome changes between the two phenotypes found in our study confirms that the number of comorbidities is not directly related to a poorer outcome following PRP 
and that, overall, comorbidities do not present a contraindication to rehabilitation access in this population [8].

The main finding of our study suggests that independent of their prevalent lung impairment and phenotype, COPD patients gain similar improvement in all the main outcome measures commonly reported during a PRP course. From a clinical point of view, it is important to note that the proportion of patients reaching MID in all outcome measures in the post-PRP evaluation was $>60 \%$ in the total population as well as in groups 1 and 2, thus confirming the valuable effect of rehabilitation in the total population of COPD patients [8,31]. This significant result may be at least partly explained on the basis of the overall high experience in rehabilitation of all the centers involved, and even reinforces the concept of the participating centers, which followed standardized and agreedupon operating procedures. On the other hand, one may argue that such impressive improvement may be ascribed to spontaneous recovery after exacerbation. Unfortunately, a limitation of this study is the lack of a control group not performing any effective PRP. Nevertheless, given the widely recognized benefits of PRP $[1,6]$, it would have been unethical to withhold such a program from this patient population.

The observed post-PRP increase in MIP and MEP deserves attention and further discussion. Indeed, the adopted standard and agreed-upon PRP did not include any specific respiratory muscle training. The activities included in our PRP, namely lifting weights and shoulder or full-arm circling, could have elicited indirect physiological effects on the abdominal and thoracic muscle compartments [32]. Nevertheless, a learning effect in performing the maneuvers cannot be excluded.

Finally, the study confirms that baseline physical performance assessed by means of the 6MWT is the only and strongest predictor of changes in exercise tolerance following PRP in the COPD population, and independent of the phenotype. This is in agreement with our retrospective study [13] and it is clearly related to the characteristics of the COPD patients included in PRP after an episode of acute decompensation [9], with a higher degree of change in the least performing individuals.

\section{Conclusions}

The present observations in a large population of COPD patients confirm that patients with either airway obstructive or parenchymal destructive phenotypes may similarly benefit from pulmonary rehabilitation in the practical clinical setting. As far as these two phenotypes are concerned, the identification of one or the other should not prevent the appropriate access to and the expected effectiveness of pulmonary rehabilitation in complex COPD patients.

The recent revision of the GOLD document has proposed that treatment of COPD be directed by clinical characteristics [1]. Considering that PRP is costly and time consuming, evaluating the impact of different COPD phenotypes on the effect of PRP becomes essential to be able to identify candidates appropriate for PRP and to help physicians in the decision-making process and ensure that patients receive rehabilitation in a timely and appropriate manner. Therefore, we believe that the results of this study are of clinical importance.

\section{Acknowledgments}

Authors and contributors acknowledge the rehabilitation teams that worked in each single center, who always operate with the scope of caring the chronic respiratory patients involved in the rehabilitation course at the level of excellence.

Other contributors to recruitment, treatment and assessment of patients: Barbara Bellofiore, MD, FCCP (Napoli); Mara Paneroni, RT and Katia Foglio, MD (Lumezzane); Katia Geraneo, MD (Montecompatri); Barbara Vagaggini, MD (Pisa); Ernesto Crisafulli, MD and Maria Cristina Lorenzi, RT (Pavullo n/F); Luca Pantani (Volterra); Gherardo Siscaro, MD (Modena).

\section{Financial Disclosure and Conflicts of Interest}

No conflicts of interest have been reported by the authors or by any individuals in the control of the content of this article.

References

1 Global Strategy for the Diagnosis, Management and Prevention of COPD, Global Initiative for Chronic Obstructive Lung Disease (GOLD). 2014, http://www.goldcopd.org/ (accessed March 2014).

-2 Vanfleteren LE, Spruit MA, Groenen M, Gaffron S, van Empel VP, Bruijnzeel PL, et al: Clusters of comorbidities based on validated objective measurements and systemic inflammation in patients with chronic obstructive pulmonary disease. Am J Respir Crit Care Med 2013;187:728-735.

-3 Pistolesi M, Camiciottoli G, Paoletti M, Marmai C, Lavorini F, Meoni E, et al: Identification of a predominant COPD phenotype in clinical practice. Respir Med 2008;102:367-376.

-4 Camiciottoli G, Bigazzi F, Paoletti M, Cestelli L, Lavorini F, Pistolesi M: Pulmonary function and sputum characteristics predict computed tomography phenotype and severity of COPD. Eur Respir J 2013;42:626-635. 
5 Singer JP, Katz PP, Iribarren C, Omachi TA, Sanchez G, Yelin EH, et al: Both pulmonary and extra-pulmonary factors predict the development of disability in chronic obstructive pulmonary disease. Respiration 2013;85:375-383.

-6 Spruit MA, Singh SJ, Garvey C, ZuWallack R, Nici L, Rochester C, et al: An official American Thoracic Society/European Respiratory Society statement: key concepts and advances in pulmonary rehabilitation. Am J Respir Crit Care Med 2013;188:e13-e64.

7 Puhan MA, Gimeno-Santos E, Scharplatz M, Troosters T, Walters EH, Steurer J: Pulmonary rehabilitation following exacerbations of chronic obstructive pulmonary disease. Cochrane Database Syst Rev 2011;5:CD005305.

$>8$ Crisafulli E, Gorgone P, Vagaggini B, Pagani M, Rossi G, Costa F, et al: Efficacy of standard rehabilitation in COPD outpatients with comorbidities. Eur Respir J 2010;36:1042-1048.

$\checkmark 9$ Clini EM, Crisafulli E, Costi S, Rossi G, Lorenzi C, Fabbri LM, Ambrosino N: Effects of early inpatient rehabilitation after acute exacerbation of COPD. Respir Med 2009;103: 1526-1531.

$>10$ Ramponi S, Tzani P, Aiello M, Marangio E, Clini E, Chetta A: Pulmonary rehabilitation improves cardiovascular response to exercise in COPD. Respiration 2013;86:17-24.

$\checkmark 11$ Ries AL, Make BJ, Lee SM, Krasna MJ, Bartels M, Crouch R, et al: The effects of pulmonary rehabilitation in the National Emphysema Treatment Trial. Chest 2005;128:3799-3809.

$>12$ Casanova C, Cote C, de Torres JP, AguirreJaime A, Marin JM, Pinto-Plata V, Celli BR: Inspiratory-to-total lung capacity ratio predicts mortality in patients with chronic obstructive pulmonary disease. Am J Respir Crit Care Med 2005;171:591-597.

13 Crisafulli E, Venturelli E, Biscione G, Vagheggini G, Iattoni A, Lucic S, et al: Exercise performance after standard rehabilitation in COPD patients with lung hyperinflation. Intern Emerg Med 2014;9:23-31.
14 Montagnani G, Vagheggini G, Panait Vlad E, Berrighi D, Pantani L, Ambrosino N: Use of the Functional Independence Measure in people for whom weaning from mechanical ventilation is difficult. Phys Ther 2011;91: 1109-1115.

15 Maltais F, LeBlanc P, Jobin J, Bérubé C, Bruneau J, Carrier L, et al: Intensity of training and physiologic adaptation in patients with chronic obstructive pulmonary disease. Am J Respir Crit Care Med 1997;155:555-556.

16 Borg G: Psychophysical basis of perceived exertion. Med Sci Sports Exerc 1982;14:377381.

17 Charlson M, Szatrowski TP, Peterson J: Validation of a combined comorbidity index. J Clin Epidemiol 1994;47:1245-1251.

18 Quanjer PH: Working party on 'Standardization of lung function test'. Bull Eur Physiopathol Respir 1983;19(suppl 5):7-10.

19 Black L, Hyatt R: Maximal airway pressures: normal values and relationship to age and sex. Am Rev Respir Dis 1969;99:696702 .

20 Bruschi C, Cerveri I, Zoia MC, Fanfulla F, Fiorentini $\mathrm{M}$, Casali L, et al: Reference values of maximal respiratory mouth pressures: a population-based study. Am Rev Respir Dis 1992; 146:790-793.

21 American Thoracic Society: ATS statement: guidelines for the six-minute walk test. Am J Respir Crit Care Med 2002;166:111-117.

22 Puhan MA, Mador MJ, Held U, Goldstein R, Guyatt GH, Schünemann HJ: Interpretation of treatment changes in 6-minute walk distance in patients with COPD. Eur Respir J 2008;32:637-643.

23 Medical Research Council, Committee on Research into Chronic Bronchitis: Instructions for Use of the Questionnaire on Respiratory Symptoms. Devon, Holman, 1966.
24 de Torres JP, Pinto-Plata V, Ingenito E, Bagley P, Gray A, Berger R, Celli B: Power of outcome measurements to detect clinically significant changes in pulmonary rehabilitation of patients with COPD. Chest 2002;121: 1092-1098.

25 Carone M, Bertolotti G, Anchisi F, Zotti AM: The St George's respiratory questionnaire (SGRQ): Italian version. Rass Patol Appar Respir 1999;14:31-37.

26 Jones PW, Quirk FH, Baveystock CM, Littlejohns P: A self-complete measure of health status for chronic airflow limitation. The St. George's Respiratory Questionnaire. Am Rev Respir Dis 1992;145:1321-1327.

27 Jones PW: Health status measurement in chronic obstructive pulmonary disease. Tho$\operatorname{rax} 2001 ; 56: 880-887$

22 Celli BR, Cote CG, Marin JM, Casanova C, Montes de Oca M, Mendez RA, et al: The body-mass index, airflow obstruction, dyspnea, and exercise capacity index in chronic obstructive pulmonary disease. N Engl J Med 2004;350:1005-1012.

29 Cote CG, Celli BR: Pulmonary rehabilitation and the BODE index in COPD. Eur Respir J 2005;26:630-636

30 Lahaije A, van Helvoort H, Dekhuijzen R, Heijdra Y: Can COPD patients who hyperinflate during daily life activities be identified by laboratory tests? Respiration 2013;86:237-242.

-31 Crisafulli E, Costi S, Luppi F, Cirelli G, Cilione C, Coletti O, et al: Role of comorbidities in a cohort of patients with COPD undergoing pulmonary rehabilitation. Thorax 2008;63: 487-492.

-32 Maltais F, Decramer M, Casaburi R, Barreiro E, Burelle Y, Debigaré R, et al: An official American Thoracic Society/European Respiratory Society statement: update on limb muscle dysfunction in chronic obstructive pulmonary disease. Am J Respir Crit Care Med 2014;189:e15-e62. 